\title{
MEDICAL MANUFACTURING INNOVATIONS
}

\author{
Cosma Sorin Cosmin ${ }^{1}$, Matei Sorin ${ }^{2}$, Vilau Cristian ${ }^{1}$ \\ ${ }^{1}$ Technical University of Cluj-Napoca, Department of Manufacturing Engineer \\ ${ }^{2}$ Bio Micron Transilvania Ltd, Department of Technology
}

\begin{abstract}
The purpose of these studies was to improve the design and manufacturing process by selective laser melting, of new medical implants. After manufacturing process, the implants were measured, microscopically and mechanical analyzed. Implants manufactured by AM can be an attractive option for surface coatings to improve the osseointegration process. The main advantages of customized implants made by AM process are: the precise adaptation to the region of implantation, better cosmesis, reduced surgical times and better performance over their generic counterparts. These medical manufacturing changes the way that the surgeons are planning surgeries and engineers are designing custom implant. AM process has eliminated the constraints of shape, size, internal structure and mechanical properties making it possible for fabrication of implants that conform to the physical and mechanical requirements of implantation according to $\mathrm{CT}$ images. This article will review some custom implants fabricated in DME using biocompatible titanium.
\end{abstract}

Keywords: Additive manufacturing, implants, mesh, cervical plate, titanium, customized

1.

Additive Manufacturing (AM) technology applications are very diverse and can be used in many fields, from industry to design or medicine. Applications of AM technologies in medicine are reported since 1994 [1,2,3,4]. These applications have led to the development of customized implants that are physical prosthetic models made for each individual case in order to accurate reconstruction of bone structure. Custom implants are presurgicaly constructed based on medical data acquired by computer tomography or nuclear magnetic resonance
Introduction using virtual 3D models and CAD/CAM techniques. Custom implants fabricated with AM have been used by different surgeons mainly for rebuilding posttraumatic or post-tumor defects in the neocranium (cranioplasties) for reconstruction of viscrocranium defects but also for other defects and/or dislocations of the human skeletal system. Preoperative manufacture of customized implants offers many advantages compared to intraoperative modeling of alloplastic implants or autogenous bone grafts.

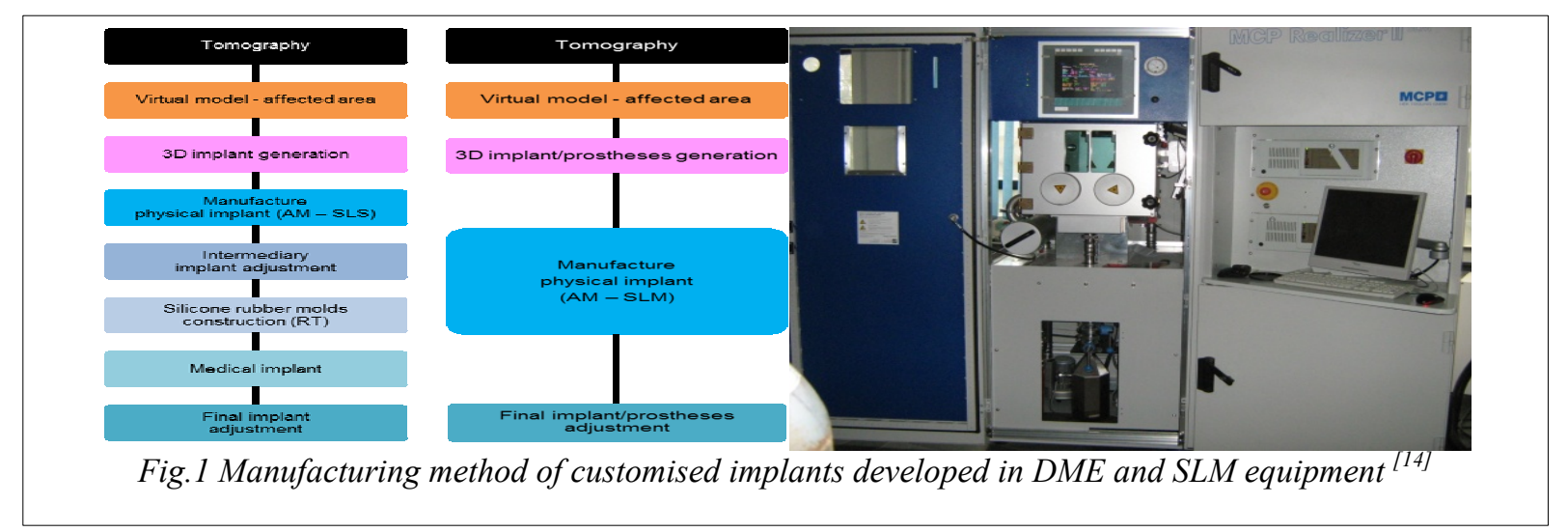


Researches in Department of Manufacturing Engineer (DME) were initiated since $1996^{[5,8]}$. It started by using silicone rubber to obtain casting molds. Some researchers ${ }^{[6]}$ have used plaster molds for casting or injection molding of implants of biocompatible materials (usually poly-methyl PM and poly-methylmethacrylate PMMA). Compared with plaster, the main advantage of silicone rubber is its elasticity ${ }^{[9]}$ that allows preservation of model's fine details during the mold release. DME research in this area in collaboration with Department of Cranio-Maxillo-Facial Surgery (University of Medicine and Pharmacy Cluj-Napoca) has started since 1998. Using technical and technological facilities which existed at that time have been produced several physical models of polyamide implants by selective laser sintering (SLS) ${ }^{[7,}$ 8 $]$. Because the polyamide is not biocompatible the model was used as the master model for manufacturing silicone rubber molds to cast the implant of polymethyl-methacrylate and poly-ethyl. Thus it was succeeded clinical to implement clinically personalized implants in viscero cranium defects reconstruction.

In figure 1 are presented two manufacturing methods of orthopedically customized implants that are elaborated up to now in DME $[10,11,12,13]$. The current research project is offering a new approach based on the existing methods. They combine the experience of the team members that summed up along the years and the modern existing equipments of DME. Researches in this domain at DME were realized, in national premiere, in the BIOMAPIM

project

(www.biomapim.utcluj.ro) by the time of 2011-2013, by an inter and transdisciplinary collective, where even the undersigned had been a part of it as a member. This study will involve more researches that have an eye on elaborating a new composite material made by two components, one organic and other inorganic, resulting a biological composite named "biocomposite".

\section{Materials and Methods}

Pure titanium powder (TILOP 45) has $45 \mu \mathrm{m}$ particle diameter, the melting point temperature around $1670^{\circ} \mathrm{C}$ and the following chemical constituents: $99.7 \% \mathrm{Ti}$, $0.08 \% \mathrm{Fe}, 0.17 \% \mathrm{O}, 0.03 \% \mathrm{C}, 0.03 \% \mathrm{~N}$, $0.01 \% \mathrm{H}$.

SLM ReaLizer 250 system (MTT Technologies, Germany) uses selective laser melting technology, an additive manufacturing process that provide $3 \mathrm{D}$ CAD data as a digital information source and energy in the form of a high-power laser beam (ytterbium fiber laser with $200 \mathrm{~W}$ maximum power) to create threedimensional metal parts by fusing fine metallic powders together.

\section{Mechanical properties}

Tensile and compressive properties were tested for the sheet specimens prepared using the SLM system at different speeds and laser power. Ultimate tensile strength $\left(\sigma_{U T S}\right)$, ultimate compressive strength $\left(\sigma_{U C S}\right)$ and Young modulus $\left(E_{Y}\right)$ were determined by manufacture of standard specimens and typical testing
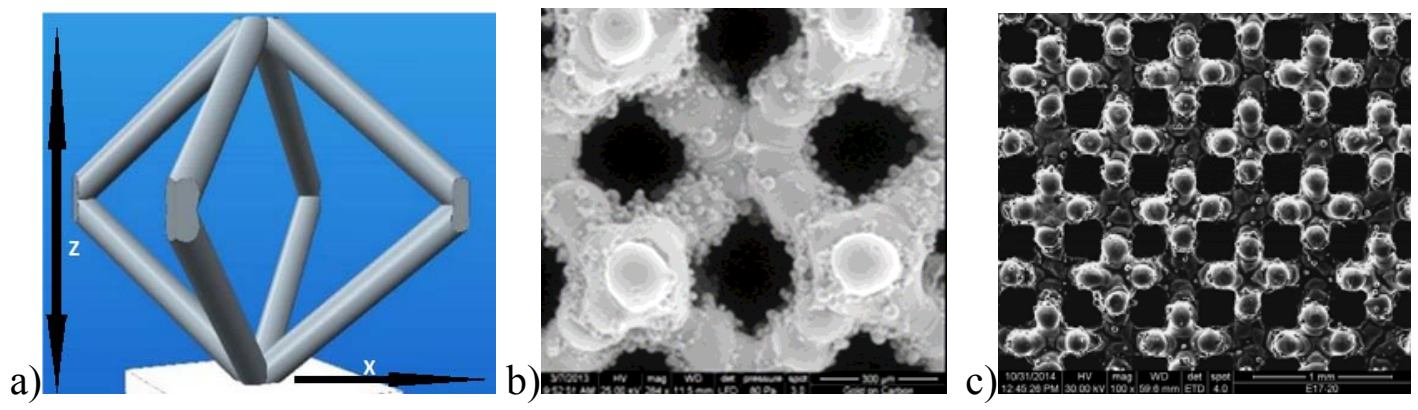

Fig.2 a) Topology of the BCC-unit cell (octahedron), b) SEM images of lattice structure composed of BBC unit before ultrasound cleaning (284x magnetization) and c) after ultrasound cleaning (100x magnetization) 
procedures employed are given in earlier researches ${ }^{[15,16,17]}$. Using the same process parameters, the tensile strength of models can easily identified in special Tables. To verify and validate the results expressed for tensile strength and Young modulus tests were performed on standard specimens by Instron 3366 equipment and extensometer INSTRON 2620-602 according to ISO 6892:2009.

\section{Porosity}

The porosity was calculated as follows:

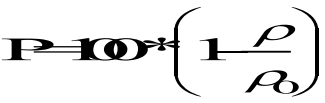

where $\rho$ is the density of the sample, obtained by the ratio weight to volume calculated by the geometrical data of this specimen and $\rho_{0}$ the material standard bulk density. The total porosity of implants, calculated based on the relationship between the measured density of the samples and the material standard bulk density. The parts were weighed with an analytical balance (Partner AS 160.R2) with $\pm 0.2 \mathrm{mg}$ precision. The implants must have at least $40 \%$ porosity to stimulate bone ingrowth. In a study by Esen and Bor ${ }^{[18]}$ a minimum porosity of $55 \%$ was reported for direct connectivity of macropores with bone.

\section{Development of macroporous parts}

Macro-porosity on parts was developing with lattice structures. This are made by elementary cell unit named bodycentered cubic (BBC) and it is an octahedron. In figure 2 is presented the used elementary cell-type develop by RDesigner software and SEM images with lattice structures manufactured by SLM. These models utilizes simple unit cell or geometrical elements which can be linearly expanded into 3D lattice structures having adjustable strut or ligament dimensions and spacing to control the porosity or density, and it is controlled via $\mathrm{x}, \mathrm{y}, \mathrm{z}$ parameters which can be from $0.4 \mathrm{~mm}$ to $\quad 1.2$ $\mathrm{mm}$ (elementary cells BBC) ${ }^{[19]}$. The cord-supported for lattice structure has a diameter between 0.195 to $0.251 \mathrm{~mm}$ and in figure 2 shows a SEM images with this type of porous structure. These structures will be used to stimulate the growth of new bone tissue into pores. These degrees of porosity would lead to an interconnected porous structure which favors the cell ingrowth to the porous space, vascularization, and transport of metabolic products. In general, implants with pore sizes in the range of 50 to $500 \mu \mathrm{m}$ are suitable for bone ingrowth ${ }^{[20,21]}$.

\section{Reconstruction of model upon patients CT images}

For customized implants, the common path is to reconstruct the model via scan-to-part: a cloud of points is reconstructed upon CT images and subsequently converted into a 3D model using MIMICS software. The model can then be manufactured through SLM technology.

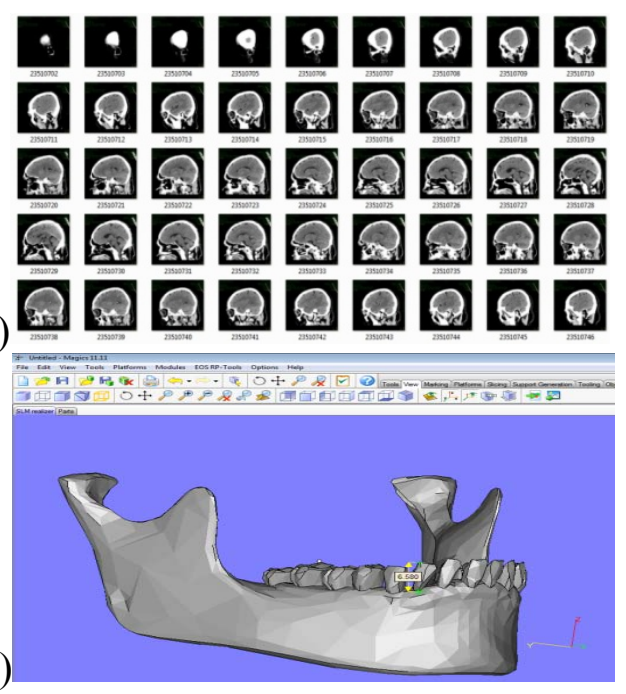

Fig. 3 a) CT images of patient head, b) 3D-CAD reconstruction of mandible

Currently, CT imaging has improved, in terms of resolution and 3D details, obtaining very accurate information from the patient. With this information, implants can be designed taking into account patient's anatomy, type of injury and surgical technique. In order to show above explained benefits of implant customization and fabrication with additive 
a)
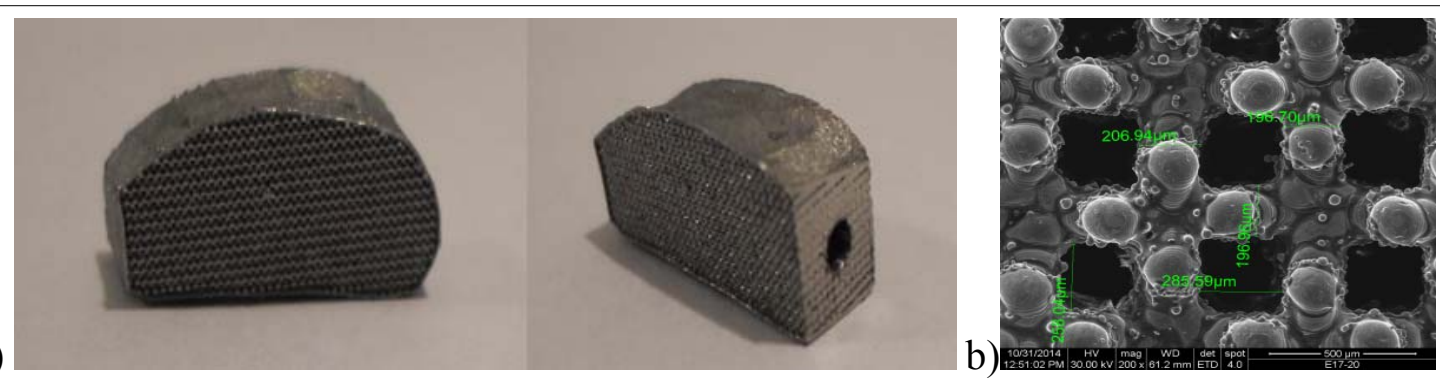

Fig. 4 a) $D_{26,27}$ pieces of mandible, fabricated by SLM with macroporous area and this lattice structure processed by CNC machining (milling and drilling), b) SEM image of lattice structure composed of BBC unit, 200x magnetization

technologies, several case studies have been made with customized implants (figure 3).

\section{Case studies}

\section{Macroporous experimental implants}

Porous regions in contact with the bone tissue promote osseointegration (direct structural and functional connection between living bone and the surface of a load-bearing artificial implant), creating better fixation between the prosthesis and the bone. Due to the fact that lattice structures allow void space for bone ingrowth, this bone ingrowth will enhance the fixation of the implant. Lattice areas also contribute to transferring loads between the implant and the bone, avoiding the previously mentioned effect of stress shielding ${ }^{[22]}$. It can be controlled the implant design and have freedom in the design of scaffolds or lattice structures (multiple geometrical solutions) for different pathologies. SLM technology manufactured these 3D geometries and after fabrication, implants will be coated with additional post-processes as plasma spray, microspheres sintering, biomimetic, etc. These lattice structures can be placed in different regions of the same implant and each lattice area could have different features (pore size, morphology, etc) if the application requires. It was possible to manufacture totally macroporous implant with only a contour having a $0.2 \mathrm{~mm}$ thickness (figure 4). Initially experiments were carried out on $\mathrm{D}_{26}$ and $\mathrm{D}_{27}$ parts, fabricated with $0.5 \mathrm{~mm} \mathrm{BBC}$ cell and the porosity obtained varies between $45-46 \%$. These parts represent a piece of real human mandible showed in figure 3 and it can be even milling by $\mathrm{CNC}$ machining or drilling to insert dental screw. According to other studies mandible bone have Young modulus between 4-25 GPa and these experimental implants have the minim value (around $5 \mathrm{GPa}$ ) ${ }^{[23]}$. Ultimate compressive strength determinate on standard samples with the same structure and process parameters was between 80-90 $\mathrm{MPa}$ and mandible bone have 80-120 MPa.

Biomechanical properties of healthy bone depend on patient age and one of the most important characteristic of bone implants is the osteointegration. The osteointegration of the grafts is related to the degree of porosity and pore size. These grafts manufactured by SLM had pore size between $250-291 \mu \mathrm{m}$ and the cordsupported for lattice structure has a diameter around $0.2 \mathrm{~mm}$ (figure $4 \mathrm{~b}$ ). Based on the literature data and also on the size of osteoblasts cells (which vary up to 20-25 $\mu \mathrm{m})$ was found that the optimum pore size have to be $50-550 \mu \mathrm{m}$ to stimulate the proliferation of osteoblasts cells ${ }^{[20,21]}$. All the implants information was detailed in Table 1.

M. Tingart et al. develop a research about cortical thickness of the proximal humeral diaphysis where anteroposterior radiographs were taken of 19 human cadaver humeri ${ }^{[24]}$. The cortical thickness was measured at two levels of the proximal humeral diaphysis. The bone mineral density was determined for the humeral head, the surgical neck, the greater tuberosity and lesser tuberosity using dualenergy X-ray absorptiometry. The mean cortical thickness was $4.4 \mathrm{~mm}$. The cortical 


\begin{tabular}{|c|c|c|c|c|c|c|c|}
\hline \multirow{2}{*}{\multicolumn{2}{|c|}{ Properties }} & \multicolumn{5}{|c|}{ Implant Model } & \multirow[t]{2}{*}{$\begin{array}{l}\text { Cortical } \\
\text { Bone }{ }^{[24]}\end{array}$} \\
\hline & & $\mathrm{D}_{26}$ & $\mathrm{D}_{27}$ & $\mathrm{E}_{1-4}$ & $E_{9-12}$ & $\mathrm{E}_{21-24}$ & \\
\hline \multirow[t]{2}{*}{$\begin{array}{l}\text { Process } \\
\text { Parameter } \\
\mathrm{s} \\
\end{array}$} & Scan Speed $[\mathrm{mm} / \mathrm{s}]$ & 375 & 300 & 1000 & 1000 & 833 & \\
\hline & Power [W] & 88 & 88 & 100 & 100 & 120 & \\
\hline \multicolumn{2}{|c|}{ Dimensional Error, $\mathrm{D}_{\mathrm{e}}[\%]$} & +0.54 & +0.57 & +0.67 & +0.45 & +0.41 & \\
\hline \multicolumn{2}{|c|}{ Porosity, P [\%] } & 46.51 & 45.65 & 37.29 & 52.54 & 44.03 & $0.4-1$ \\
\hline \multicolumn{2}{|c|}{ Young Modulus, $\mathrm{E}_{\mathrm{Y}}[\mathrm{GPa}]$} & 5.01 & 5.01 & 7.53 & 8.38 & 13.69 & $4-25$ \\
\hline \multirow{2}{*}{\multicolumn{2}{|c|}{$\begin{array}{l}\text { Compressive yield streght, } \sigma_{0.2}[\mathrm{MPa}] \\
\text { Ultimate compressive strength, } \sigma_{\mathrm{UCS}}[\mathrm{MPa}]\end{array}$}} & - & - & 157.87 & 172.65 & 256.34 & \\
\hline & & 89 & 81 & 294.32 & 335.48 & 512.59 & $\begin{array}{l}145-190 \\
79-120\end{array}$ \\
\hline \multirow{3}{*}{$\begin{array}{l}\text { Roughness } \\
\text { on Z-axis }\end{array}$} & $\mathrm{R}_{\mathrm{a}}[\mu \mathrm{m}]$ & 10.64 & 11.78 & 11.08 & 10.22 & 12.05 & \\
\hline & $\mathrm{R}_{\mathrm{z}}[\mu \mathrm{m}]$ & 61.27 & 68.34 & 59.38 & 59.79 & 68.11 & \\
\hline & R 「ит? & 1450 & 1507 & 1256 & 1781 & 1407 & \\
\hline
\end{tabular}
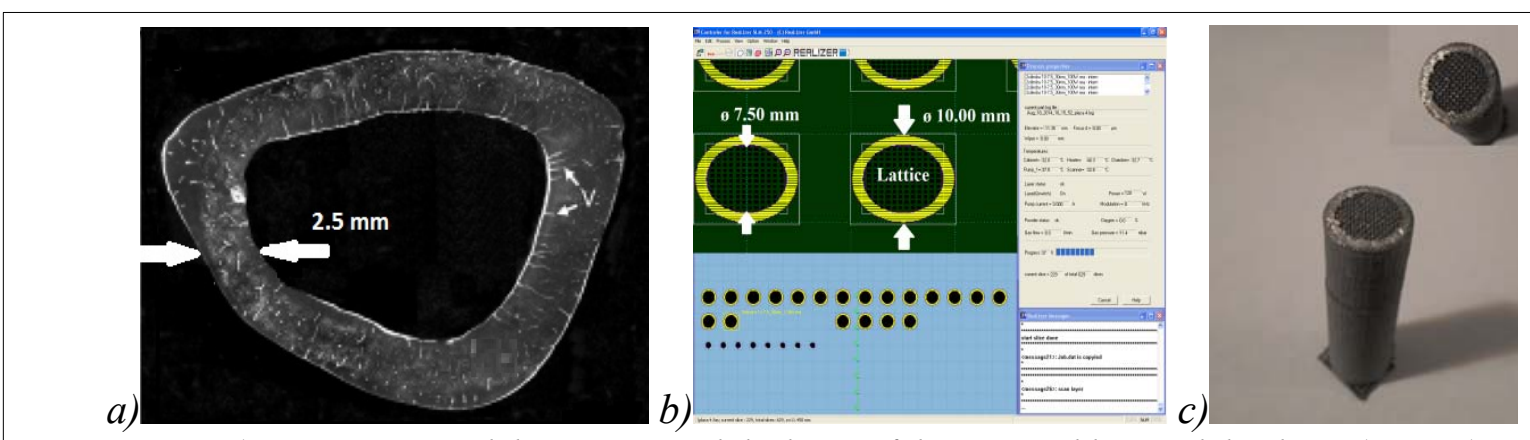

Fig.5 a) X-ray image with human cortical thickness of the proximal humeral diaphysis (2.5 mm),

b) Experimental implants designed similar to human bone with $25 \%$ compact zone (full dense) and $75 \%$ trabecular area (structural porosity made from lattice structure) on SLM equipment software,

c) $E_{1-4}$ models after manufacturing

thickness of the proximal diaphysis is a reliable predictor of the bone quality of the proximal humerus ${ }^{[24]}$. In order to develop a similar bone implant like real human bone was developed experimental implants namely $\mathrm{E}_{1-4}, \mathrm{E}_{21-24}$ and $\mathrm{E}_{9-12}$. These experimental implants have the form of cylinder with different macro-porosity designed in RDesigner and various values for BBC cell like: $x=y=z=0.5 \mathrm{~mm}\left(E_{1-4}\right)$, $\mathrm{x}=\mathrm{y}=\mathrm{z}=0.6 \mathrm{~mm}\left(\mathrm{E}_{21-24}\right)$ and $\mathrm{x}=\mathrm{y}=\mathrm{z}=0.7 \mathrm{~mm}$ $\left(\mathrm{E}_{9-12}\right)$, being in accordance with the human bone (cortical and trabecular tissue). The full dense area represents the cortical bone (2.5 $\mathrm{mm}$ thickness) and lattice structures have similar construction like trabercular bone $\quad$ (7.5 mm thickness) presented in figure 5 .

As summarized in Table 1, the elastic moduli of SLM-processed samples were 5-13 GPa for porous parts which have the porosity levels of $37 \%$ to
$52 \%$. As evident, Young's moduli of all samples are much lower than those of 316L stainless steel

$(210 \mathrm{GPa})$ and chromium cobalt alloys

(240 GPa) which have been used as surgical implants for the past years. More importantly, porous samples with this porosity show an elastic modulus similar to human bone (4-25 GPa). This low range of Young's modulus can prevent stress shielding effect and consequently revision surgery. These promising results of low elastic modulus samples resulting from SLM with porous samples could be applicable for biomedical implants.

In these initial experiments, after SLM process the surface roughness of parts has values for $R_{a}$ between 10 to $12 \mu \mathrm{m}$ and it need to be improved. Further studies are needed to determine all the physicomechanical characteristics and compare to human bone. 


\section{Cervical plate}

The anterior cervical plate system presented in figure 6 is a ratcheting plate featuring segments that translate under compression, but maintain their position under tension. Test results demonstrated that the unidirectional plate had less motion in flexion-extension and maintained a more consistent graft load when compared to bidirectional design. This system is intended for use in temporary stabilization of the anterior cervical spine during the development of spinal fusions in patients with: degenerative disc disease, trauma, tumors, deformity, pseudoarthrosis, and failed previous fusions ${ }^{[26]}$. Spinal implants made from titanium are used in cases where bioabsorbable anterior cervical plates would not be sufficiently robust. It is important to stabilize the spine with a stronger spinal implant for a better fixation. Dr. Dachs obtained a successful, safe and reliable procedure for the correction of thoracolumbar and lumbar scoliosis using instrumented anterior spinal fusion ${ }^{[25]}$. It provides effective deformity correction and good maintenance of the correction. Fusion can be limited to the major structural curve, with reliable spontaneous correction of the thoracic curve (figure $6 \mathrm{a}, \mathrm{b}$ ).

There are currently a multitude of dynamic plates available, with new designs being frequently introduced. Dynamic anterior plates have been popularized to controlled settling, thereby promoting load sharing across the construct. A current study compares similar patients and demonstrates no clear advantage of the use of a dynamic plate over the cheaper, simpler static plate after multilevel anterior cervical discectomy and fusion for degenerative pathologies ${ }^{[27]}$.

Considering this study, figure 6 presents also the 3D design of a customized spinal prosthesis and the final product obtained through additive manufacturing process (SLM). It was fabricated 3 customized cervical plate with 6 threaded holes and the plate have a thickness of $\quad 1.8 \mathrm{~mm}$, a width of $8.4 \mathrm{~mm}$ and a length of $66.8 \mathrm{~mm}$. For fabrication was used process parameters mention in Table 2 and the mechanical properties obtained was similar to external fixators because it was used the same process parameters. The surface roughness presents in Table 2 was obtained with-out any post-processing treatment. This customized cervical plate fabricated by AM process was used in a clinical study develop by surgeons from "Victor Papilian" Faculty of Medicine, "Lucian Blaga" University of Sibiu.

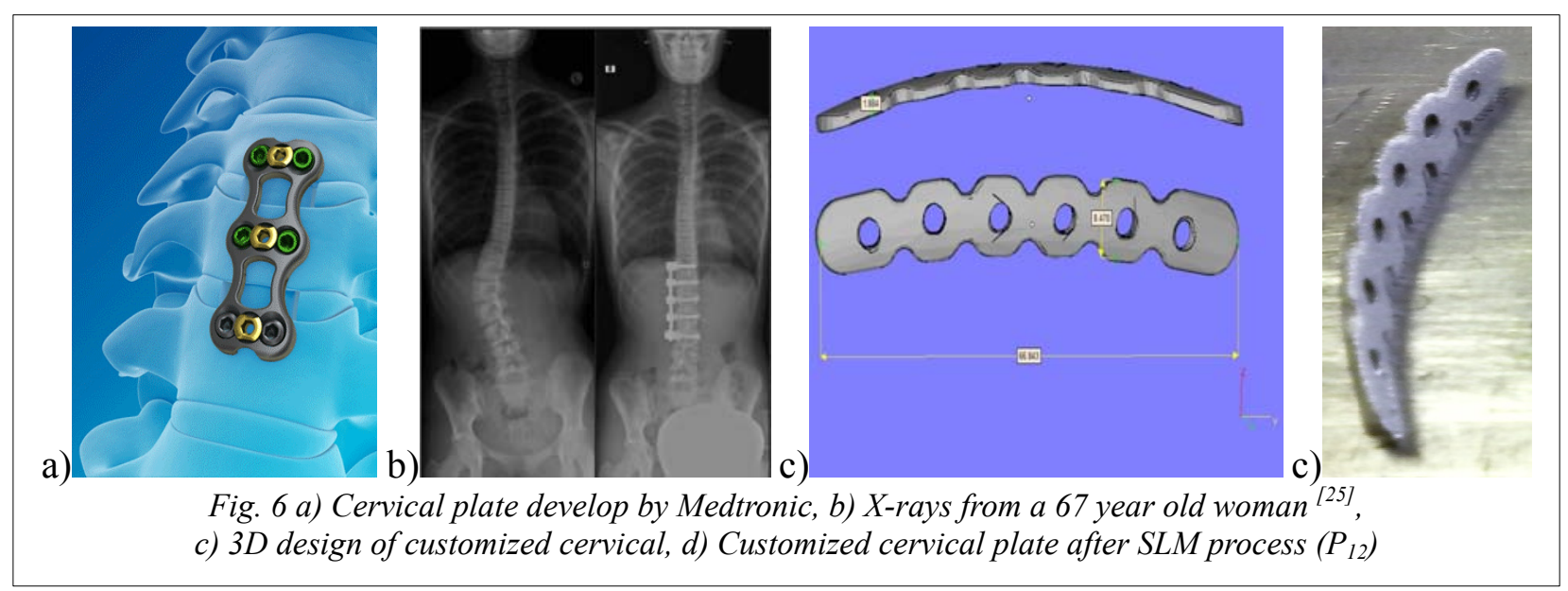

promote cervical spine fusion by allowing

Midface reconstruction 

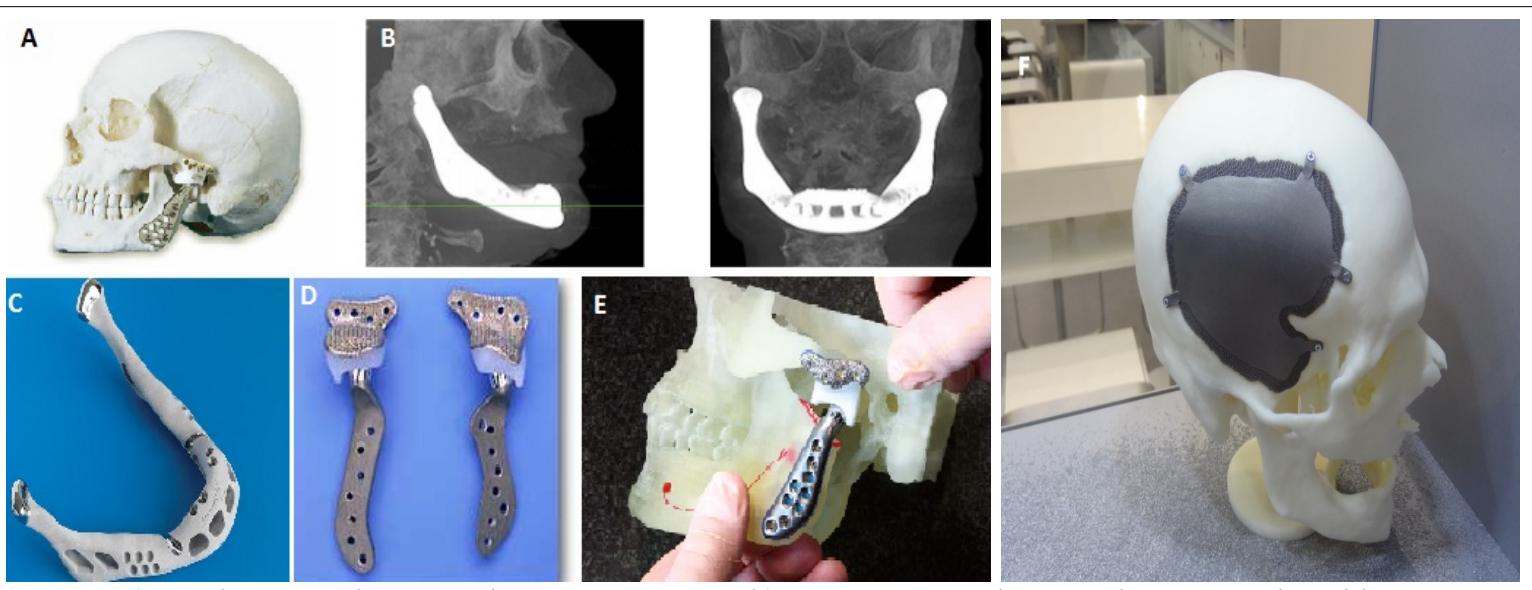

Fig. 7 a) Total joint replacement by TMJ Concepts, b) X-ray images showing the AM-produced lower jaw reconstruction implanted into the patient (left: side view; right: front view), c) The 3-D printed custom-made implant was coated with hydroxyapatite, University of Hasselt, d) and e) Temporomandibular joint produce through CNC machining, f) Titanium porous cranial implant fitting to the cranium mode, Concept Laser

TMJ concepts manufacture patientfitted prostheses for reconstruction of the temporomandibular joint, customizing the joint allows for maximum fixation. The condylar head is made of cobaltchromium-molybdenum, and the body is composed of titanium alloy. Pure titanium mesh is used for the fabrication of the mandibular fossa, and its articular surface is made of ultra-high-olecular-weight polyethylene (figure 7).

The world's first additive manufactured full mandible was implanted in a patient by Dr. Jules Poukens and his team in Belgium is seen in figure $7 \mathrm{~b}$ ) and c). In recent years the model of the cranium with the defect is fabricated using additive manufacturing technologies. Figure 7f) shows a large titanium mesh cranioplasty implant with porous contact area.
Using bioresorbable materials, implants can be manufactured which dissolve in the human body and are replaced by natural bone structure. For large implants an interconnecting porous structure should be integrated in the implant for a good vascularisation. Additive manufacturing technology can directly develop these internal structures. The structure can be designed by consequent following the guidelines of the medical expert. Figure 9 presented a cranial implant made of composite powder ( $\beta$-TCP / PDLLA) abricated by SLS process ${ }^{[28]}$. The mechanical properties of fabricated test geometries are in the medium to high range of human cancellous bone and the implants are therefore suitable for application in non load-bear-ing bone defects. In vitro experiments show good

a)
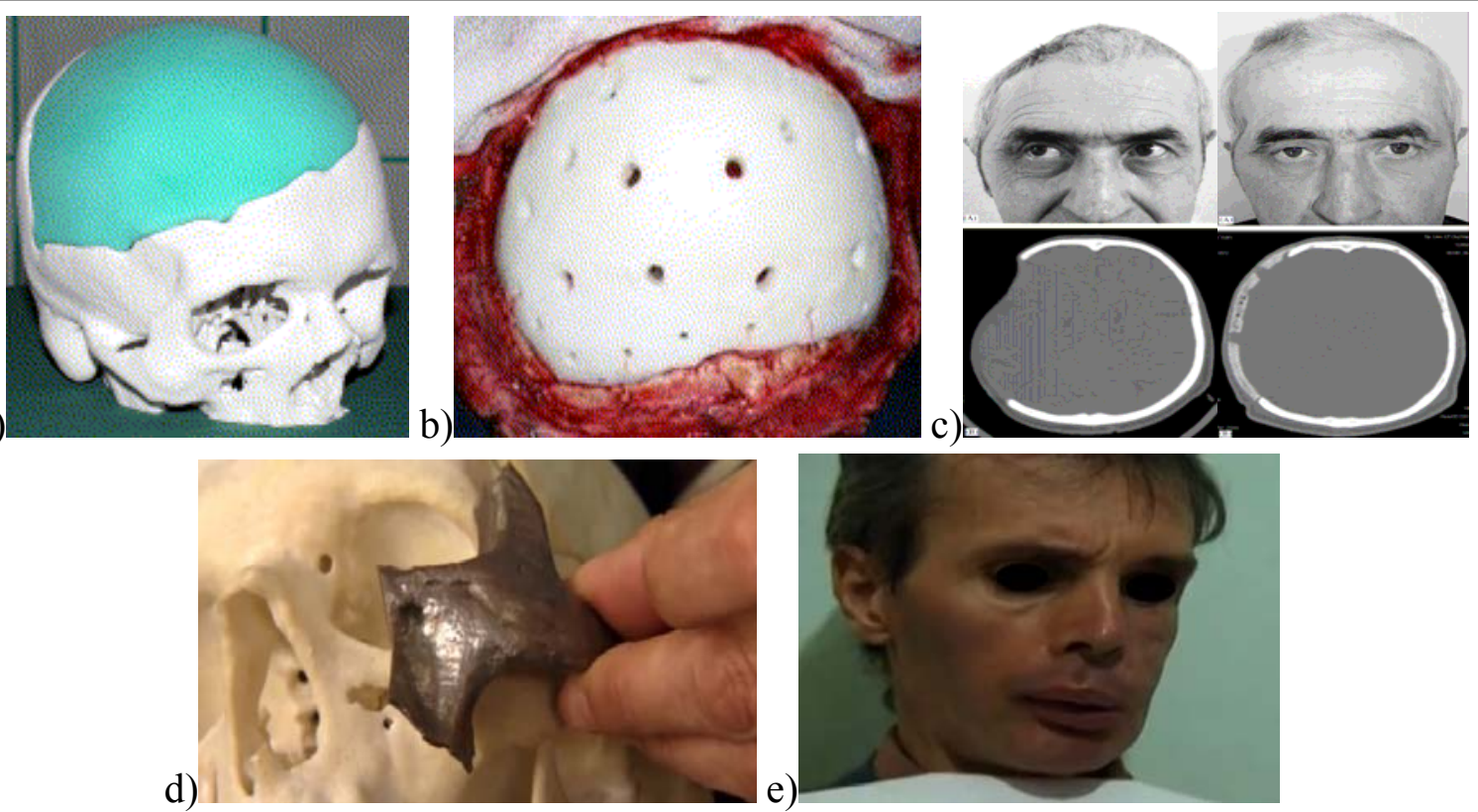

Fig. 8 3D reconstruction of patient specific implants made in DME, a) Master model of implant, polymethylmethacrylate implant, c) Patient before and after reconstruction surgery, d) Reconstruction of patient specific titanium implant, e)Patient after 4 - 
proliferation and no cytotoxicity of human osteoblasts on SLM test geometries.

In the right side of figure 9 it can be seen the same 3D CAD model of zygomatic bone previously presented manufactured also by selective laser sintering. The white powder PA 2200 has high strength and stiffness, good chemical resistance, excellent long-term constant behavior, high selectivity and detail resolution, biocompatible according to EN ISO 10993-1 and thermal conductivity $0.144 \mathrm{Wm}^{-1} \mathrm{~K}^{-1}$. This powder is recommended to medical applications (e.g. prostheses) because it has a low thermal conductive value.

Figure 9 shows another method that was used to produce customized implants with the following steps: 3D CAD reconstruction, fabricated the master model of implant by SLS process and PA 2200 powder material, create a silicone rubber mold with the master model and then in this mold was fabricated the implant from a polymethylmethacrylate material (PMMA). PMMA was used as the reconstruction material and these personalized implants were developed for 10 patients (9 men and 1 woman) who previously received a craniectomy. The symmetry gained after cranioplasty was quantified by volumetric analysis using 3D reconstructed postoperative computed tomographic imaging. No infectious episodes or signs of plate rejection were encountered and the custom-made implants

\begin{tabular}{|c|c|c|c|c|c|}
\hline \multirow{2}{*}{\multicolumn{2}{|c|}{ Properties }} & \multicolumn{4}{|c|}{ Implant Model } \\
\hline & & $\mathrm{B}_{1}$ & $\mathrm{P}_{12}$ & $\mathrm{~F}_{7}$ & $\mathrm{~F}_{8}$ \\
\hline \multirow[t]{2}{*}{$\begin{array}{l}\text { Process } \\
\text { Parameters }\end{array}$} & $\begin{array}{l}\text { Scan } \\
\text { Speed } \\
{[\mathrm{mm} / \mathrm{s}]}\end{array}$ & 400 & 400 & 833 & 833 \\
\hline & $\begin{array}{l}\text { Power } \\
\text { [W] }\end{array}$ & 120 & 120 & 120 & 120 \\
\hline \multicolumn{2}{|c|}{$\begin{array}{l}\text { Dimensional Error, } \\
D_{\mathrm{e}}[\%]\end{array}$} & $\begin{array}{l}+ \\
0.2\end{array}$ & $\begin{array}{l}+ \\
0.2\end{array}$ & +0.6 & +0.7 \\
\hline \multicolumn{2}{|c|}{ Porosity, P [\%] } & 0.5 & 0.4 & 33.4 & 57.8 \\
\hline \multicolumn{2}{|c|}{$\begin{array}{l}\text { Young Modulus, } \\
\mathrm{E}_{\mathrm{Y}}[\mathrm{GPa}]\end{array}$} & 96.7 & 96.7 & 45.4 & 18.2 \\
\hline \multicolumn{2}{|c|}{$\begin{array}{l}\text { Yield tensile strength, } \\
\sigma_{0.2}[\mathrm{MPa}]\end{array}$} & 410 & 410 & \multirow{5}{*}{\multicolumn{2}{|c|}{$\begin{array}{c}\text { Was not } \\
\text { possible to } \\
\text { analyze } \\
\text { because of } \\
\text { their shape }\end{array}$}} \\
\hline $\begin{array}{l}\text { Ultimate ter } \\
\text { strength, } \sigma\end{array}$ & $\begin{array}{l}\mathrm{ile} \\
\mathrm{SPa}]\end{array}$ & 441 & 441 & & \\
\hline \multirow{3}{*}{$\begin{array}{l}\text { Roughnes } \\
\text { s }\end{array}$} & $\mathrm{R}_{\mathrm{a}}[\mu \mathrm{m}]$ & 2.1 & 10.2 & & \\
\hline & $\mathrm{R}_{\mathrm{z}}[\mu \mathrm{m}]$ & 10.7 & 59.7 & & \\
\hline & $\mathrm{R}_{\mathrm{q}}[\mu \mathrm{m}]$ & 3.5 & 12.8 & & \\
\hline
\end{tabular}

for cranioplasty showed a significant improvement in morphology. The implants could be very useful for repairing large and complex-shaped cranial defects and bone reconstruction of other sites ${ }^{[29,30]}$.

Figure 8 d) and e) shows the zygomatic implant manufactured by SLM in our department before and after post-processing. A similar implant was donated to a man (45 years old) in distress, who suffering a car accident and the left side of midface was completely destroyed (zygomatic bone). The advantage of this titanium implants compared to implants made from plastic (polymethyl methacrylate PMMA) is that titanium is more stable and is integrated into the bone structure. The surgical act and implant method for manufacturing was an

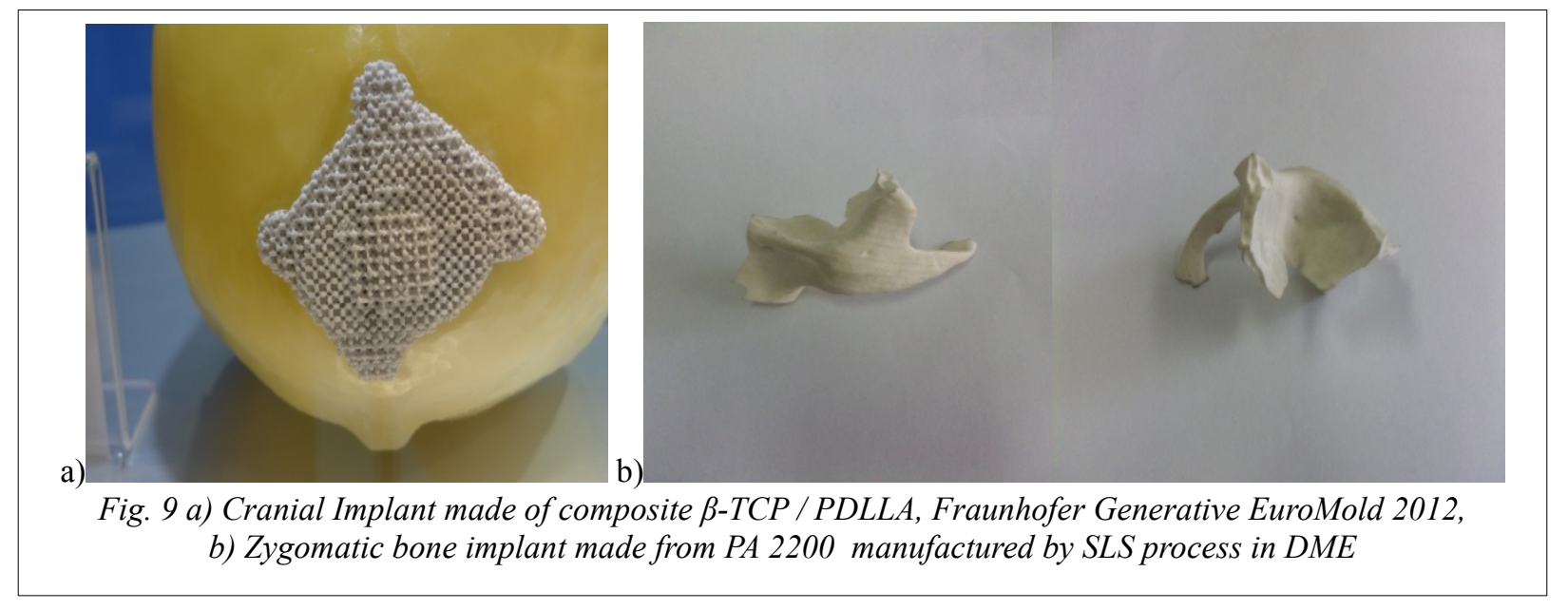


a)
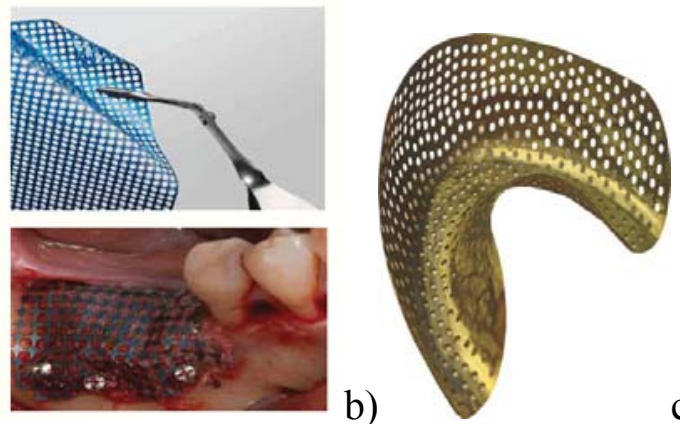

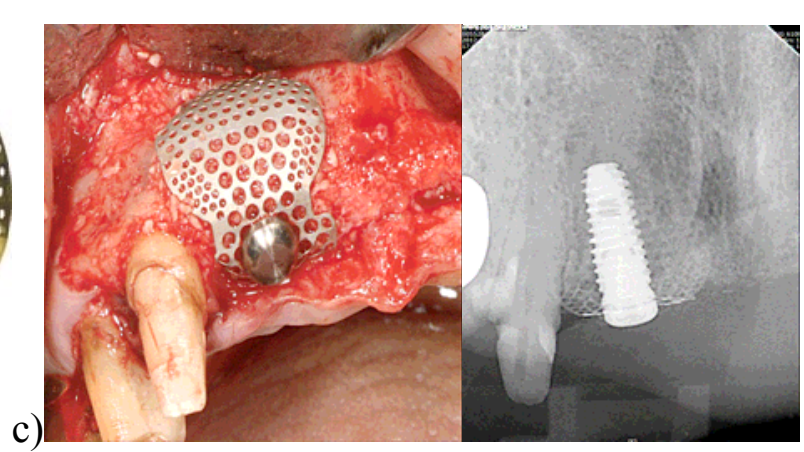

Fig. 10 a)Micro Mesh, omnia maxil surgical procedure to fix the titanium mesh, b) Preformed titanium Q-Mesh, c) A customized, 3-dimensional, and preformed titanium mesh (SMART builder type II, Osstem) was connected to the height, placed over the graft material, and stabilized by the cover cap ${ }^{[34]}$

international premier because, so far such customized titanium implants were used only to reconstruct the mandible. The surgery team of doctors was conducted by Dr. H. Rotaru. The result of the surgery was a success, and after four months the implant was perfectly integrated in the body without any signs of rejection ${ }^{[31]}$. Psychological condition of the patient was also greatly enhanced by reintegrating into the community.

\section{Titanium customized mesh}

Meshes and membranes of titanium are used as protection for bone reconstruction and they are available in different sizes and thicknesses to could adapt for any bone defect (figure $10 \mathrm{a}$ and b). The $0.2 \mathrm{~mm}$ thick meshes ensure a better stabilization in case of serious bone defects, whereas $0.1 \mathrm{~mm}$ thick meshes are easier to adapt to any kind of bone defect. For mesh stabilization is used titanium micro-screws with 1.5-1.7 mm diameter.

Figure 10 c) presented a customized, three-dimensional, and preformed titanium mesh used in combination with autologous bone induced successful bone regeneration in periimplant defects occurring after implant placement. Even in the cases of titanium mesh exposure, this preformed titanium mesh produced reliable outcomes as a barrier membrane. This preliminary study shows histologic evidence of satisfactory vital bone formation in the augmented area. Preformed titanium mesh supports the grafted space for new bone formation, makes application and removal convenient, and minimizes the risk of mesh exposure in the reconstruction of peri-implant alveolar bone defects ${ }^{[33]}$. In order to this study and other in this field ${ }^{[34,35]}$ it was designed and manufactured 2 types of mesh named $\mathrm{F}_{7}$ and $F_{8}$ (figure 11) and they had the thickness $0.2 \mathrm{~mm}$ and $0.6 \mathrm{~mm}$. $\mathrm{F}_{8}$ mesh was designed with different diameters of holes $\quad(\varnothing 1.5 \mathrm{~mm}$ to $\varnothing 1.7 \mathrm{~mm})$ to see the accuracy of SLM equipment.

Factors such as osteogenic potential of the host residual bone, systemic health of patients, and morphology of the defects, will delimit the ideal bone substitute for each situation. For example in sinus augmentation, allografts, xenografs and synthetic calcium phosphates have been used as alternative to autografts with high rate of implants success and survival. To improve the osseointegration all the implants have special surface treatments. Among these are infiltration of hydroxylapatite (HA), $\beta$-TCP, enzymes, growth factors or other drugs and biomimetic coating. 


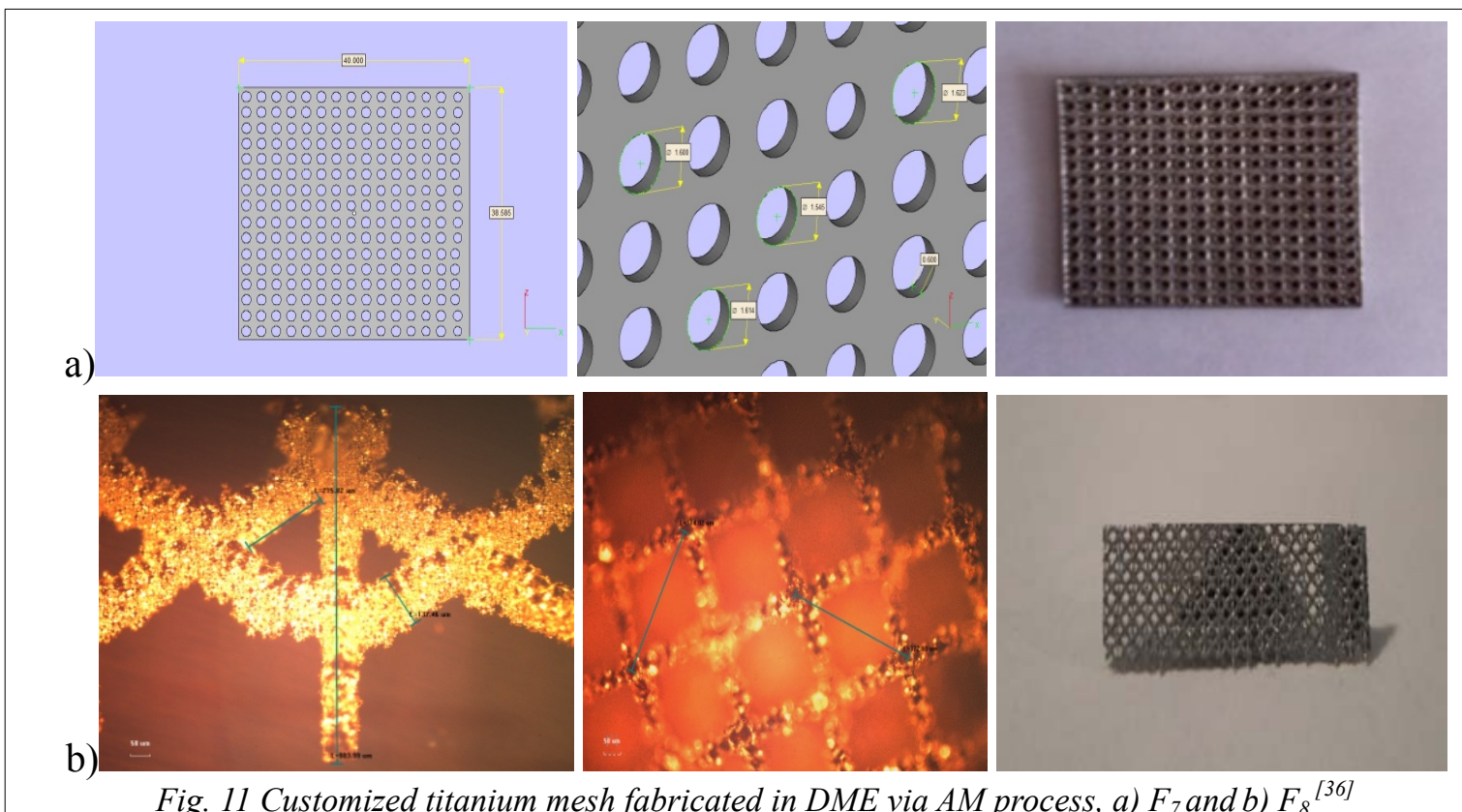

\section{Conclusions}

There are different researches attempts being performed along the world in order to obtain new findings applicable to new biomedical implants and for supporting the biomedical industry. These days, the main object is to combine porous medical applications manufactured by SLM technology with a variety of surface modification techniques developed in orthopedics and they have been successfully adapted to implants.

Engineers and surgeons are leading towards the emergence of a new specialization as bio CAD/CAM that will make possible emergence of patient specific implants that will replicate not only form as it is today but also have mechanical, chemical and physiological properties similar to native tissues they replace and provide an environment for cell differentiation and growth.

Further researches will include in vivo test, to check the proliferation of bone cells and the ingrowth osseointegration process on these porous implants made by SLM process. The mechanical properties of titanium and its alloys can be adapted to the requirements of patients to be more friendly.

\section{Acknowledgment}

This paper is supported by the Sectoral Operational Programme Human Resources Development POSDRU/159/1.5/S/137070 financed from the European Social Fund.

\section{References}

1. E.C. Santos, M. Shiomi, K. Osakada, T. Laoui, "Rapid Manufacturing of metal components by laser forming", International Journal of Machine Tools and Manufacture, Volume 46, Issues 12-13, pp. 1459-1468, 2006;

2. B. Vandenbroucke, J. Kruth, "Selective laser melting of biocompatible metals for rapid manufacturing of medical parts", Rapid Prototyping Journal, Volume 13 Issue 4, ISSN 1355-2546, 2007, FI 0.700;

3. J.P. Kruth, B. Vandenbroucke, J. Van Vaerenbergh, I. Naert, "Digital Manufacturing of biocompatible metal frameworks for complex dental prostheses by means of SLS/SLM", Proc. of 2nd Int. Conf. on Advanced Research in Virtual and Rapid Prototyping, Leiria, pp. 139-145, Sept. 2005;

4. J.P. Kruth, B. Vandenbroucke, J. Van Vaerenbergh, P. Mercelis, "Benchmarking of Different SLS/SLM Processes as Rapid Manufacturing Techniques", Proc. of 1st 
Int. Conf. of Polymers and Moulds Innovations, Gent, April 2005;

5. N. Balc, "Medical Applications of Rapid Prototyping", Proceedings of the Layered Technologies Workshop.

ISBN 8643506168 , University of Maribor, Slovenia, pp. 58-65, April 2004;

6. P. Berce, H. Chezan, N. Balc, "The application of Rapid Prototyping Technologies for manufacturing the custom implants". 8th ESAFORM Conference on Material Forming, Cluj-Napoca, pp. 27-29, ISBN 9732711752, April 2005;

7. H. Rotaru, S. Bran, G. Baciut, M.F. Baciut, et al., "Silicone-rubber moulding of custom-made cranioplasty plates". Monduzzi Editore International Proceedings Division, ISBN 88-7587-2813,3:15-9, 2006;

8. H. Rotaru, M.F.Baciut, H. Stan, S.Bran, et al., "Silicone rubber mould cast polyethylmethacrylate-hydroxyapatite plate used for repairing a large skull defect". Journal of Cranio-Maxillofacial Surgery, Volume 34, Issue 4,

pp. 242246, 2006;

9. S.A. Radu, D. Fratila, "Simulation and experimental research on the vacuum casting of non-metallic complex parts using flexible molds", Proceedings of the Romanian Academy series A, ISSN 14549069, Volume 13, Number 4, pag. 343-350;

10. H. Rotaru, G. Armencea, D. Spirchez, C. Berce, T. Marcu, D. Leordean, S. Kim, M Bacit, "In vivo behavior of surface modified Ti6Al7Nb alloys used in selective laser melting for custom-made implants. A preliminary study", Romanian Jounal of Morphology and Embryology, Vol. 54 - Issue 3 Suppl., 2013, ISSN 12200522, pp. 791-796;

11. T. Marcu, M. Todea, L. Maines, D. Leordean, P. Berce, C. Popa, "Metallurgical and mechanical characterisation of titanium based materials for endosseous applications obtained by selective laser melting", Powder Metallurgy, Volume: 55, Issue: 4, Pages:
309-314, Published: SEP 2012, IDS Number: 036NI;

12. T. Marcu, C. Menapace, L. Girardini, D. Leordean, C. Popa, "Selective Laser Melting of Ti6Al7Nb with hydroxyapatite addition", Rapid Prototyping Jornal, Volumul: 20, Issue: 4, ISSN: 1355-2546, pp. 301-310;

13. V. Saplontai, M. Saplontai, D. Leordean, M. Moldovan, et al., "Electrochemical and structural investigation on Ti6Al7 Nb alloy, coated with hydroxyapatite and tanium dioxide", Chemistry Magazine, Bucharest, Volume: 2014, Issue: 10, October 2014, ISSN: 0034-7752, pag. 1249-1252;

14. D. Leordean, "Cercetări teoretice i experimentale privind utilizarea tehnologiilor RP în fabrica ia de implanturi ortopedice personalizate", $\mathrm{PhD}$ thesis, UTCN, 2011;

15. S. Muresan, N. Balc, D. Pop, I. Fodorean, "Influence of Process Parameters To Manufacture Titanium Parts By SLM", The 10-th International MTeM Conference Proceedings, pag. 210-213, Cluj-Napoca 6-8 October 2011, Romania;

16. S. Muresan, "Research on mechanical properties of complex parts manufactured by selective laser melting", $\mathrm{PhD}$ Thesis, Technical University of ClujNapoca, 2011;

17. D. Lerodean, "Theoretical and experimental research of Rapid Prototyping technologies for customized orthopedic implants", $\mathrm{PhD}$ Thesis Technical University of Cluj-Napoca, 2011;

18. Z. Esen, S. Bor, "Processing of titanium foams using magnesium spacer particles", Scripta Materialia, 2007, Vol. 56, 341-344;

19. S.C. Cosma, N. Balc, D. Leordean, S. Matei, "Dental implants with lattice structure fabricated by Selective Laser Melting". International Virtual Research Conference in Technical Disciplines, Slovakia, ISSN: 1339-5076, pp. 18-23, (2014);

20. R.W. Bucholtz, "Nonallograft osteoconductive bone graft substitutes", 
Clinical Orthopaedic and Related Research, 2002, Vol. 395, 44-52;

21. A. Laptev, M. Bram, $H$. Buchkremer, D. Stöver, "Study of production route for titanium parts combining very high porosity and complex shape", Powder Metallurgy, 2004, Vol. 47, 85-92;

22. V. Petrovic, J. Haro, J. Blasco, L. Portolés, "Additive Manufacturing Solutions for Improved Medical Implants", Biomedicine, Dr. Chao Lin (Ed.), ISBN: 978-953-51-0352-3, InTech, 2012, DOI: 10.5772/38349;

23. A. Kemper, et al. "The material properties of human tibia cortical bone in tension and compression: Implications for the tibia index." Proceedings of the 20th Enhanced Safety of Vehicles Conference, Lyon, France, 2007;

24. J. Tingart, M. Apreleva, D.von Stechow, D. Zurakowski, J. Warner, "The cortical thickness of the proximal humeral diaphysis predicts bone mineral density of the proximal humerus", Markus From Harvard Medical School, Boston, USA;

25. R.P. Dachs, R. Dunn, "Anterior surgical correction of thoracolumbar and lumbar scoliosis: efficacy and morbidity". SA Orthop. J., 2013, vol.12, n.1, pp. 25-29; 26. D. DiAngelo, J. Roberson, D. Karahalios, B. Kelly, T. Bonvallet, E. Potts, A. Vaccaro, "Use of Compliant Interbody Load Cells to Compare Load Sharing Properties of Unidirectional and Bidirectional Multilevel Dynamic Translational Anterior Cervical Plates", Memphis TN: Medtronic, 2008;

27. M. Christian, D. Bois, et al., "Static versus dynamic plating for multilevel anterior cervical discectomy and fusion", The Spine Journal 7 (2007), pp. 188193;

28. S. Hoeges, M. Lindner, W. Meiners, R. Smeets, "Bioresorbable Implants using Selective Laser Melting" SFF Symposium, 2010;

29. H. Rotaru, et al., "Cranioplasty With Custom-Made Implants: Analyzing the Cases of 10 Patients", Journal of Oral and Maxillofacial Surgery, Volume 70 , Issue 2 , e169 - e176;

30. H. Rotaru, M. Baciut, H. Stan, S. Bran, H. Chezan, A. Iosif, M. Tomescu, S.G. Kim, Al. Rotaru, Gr. Baciut, "Silicone rubber mould cast polyethylmethacrylatehydroxyapatite plate used for repairing a large skull defect", Journal of CranioMaxillofacial Surgery, vol. 34, nr. 4, pp. 242-246, 2006;

31. H. Rotaru, et al., "Selective laser melted titanium implant for the zygomatic bone reconstruction. Report of a case.", XXII Congress of the European Association for Cranio-Maxillo-Facial Surgery 23-26 September 2014, Prague, Czech Republic;

32. http://www.omniaspa.eu

33. G. Jung, J. Jeon, K. Hwang, C. Park, "Preliminary evaluation of a threedimensional, customized, and preformed titanium mesh in peri-implant alveolar bone regeneration", J. Korean Assoc Oral Maxillofac. Surg. 2014; 40:181187 ;

34. A. Lundgren, L. Sennerby, D. Lundgren, A. Taylor, J. Gottlow, S. Nyman, "Bone augmentation at titanium implants using autologous bone grafts and a bioresorbable barrier. An experimental study in the rabbit tibia", Clin. Oral Implants Res 1997;8:82-9;

35. P. Proussaefs, J. Lozada, "Use of titanium mesh for staged localized alveolar ridge augmentation: clinical and histologichistomorphometric evaluation", J. Oral Implantol 2006; 32:237-47;

36. www.biomicron.eu. 